\title{
O PRINCÍPIO DA IMEDIAÇÃO NO PROCESSO CIVIL EM PORTUGAL EM \\ TEMPOS DE PANDEMIA: A REALIZAÇÃO DAS AUDIÊNCIAS POR VIDEOCONFERENCIA ${ }^{1}$
}

\section{THE PRINCIPLE OF IMMEDIACY IN PORTUGUESE CIVIL PROCEDURE IN TIMES OF PANDEMIC: THE USE OF VIDEOCONFERENCING HEARINGS IN JUDICIAL PROCEEDINGS}

Rita Lynce de Faria Professora Auxiliar da Faculdade de Direito da Universidade Católica Portuguesa. Mestre e Doutora pela Universidade Católica Portuguesa. Integra o Católica Research Centre for the Future of Law, com publicações e pesquisas nas áreas do Direito Civil e do Direito Processual Civil, sobretudo em matéria de providências cautelares. Exerceu funções diretivas enquanto membro do Conselho de Direção da Escola de Lisboa da Faculdade de Direito da Universidade Católica Portuguesa. Consultora na sociedade SRS Advogados e coordenadora executiva do Centro de Arbitragem da Universidade Católica Portuguesa. Lisboa, Portugal. E-mail: rlynce@ucp.pt

RESUMO: O presente artigo visa averiguar de que forma o regime de realização de audiências por videoconferências, instituído pela Lei 1-A/2020 de 19 de Março, afetou o princípio da imediação. Para tanto, será trabalhado o sentido e significado do princípio da imediação, se exporá a forma de realização das audiências de julgamento durante o período da pandemia e, por fim, será avaliado se houve ou não efetiva violação do princípio da imediação.

PALAVRAS-CHAVE: Princípio da imediação; audiência por vídeo conferência; pandemia

\footnotetext{
${ }^{1}$ Artigo recebido em 06/10/2021, sob dispensa de revisão.
} 
do novo Coronavírus (COVID-19); Código de Processo Civil português.

ABSTRACT: The article aims to investigate how the use of videoconferencing hearings in Portuguese judicial proceedings, established by Law 1-A/2020 of March $19^{\text {th }}$, affected the principle of immediacy. To achieve it goals, this paper will analyze the meaning and definition of the mentioned principle. In addition to that, it will be highlighted the conduction of the hearings during the pandemic scenario. Last but not least, it will be evaluated whether or not there has been an effective violation of the principle.

KEYWORDS: Principle of immediacy; videoconferencing hearings; coronavirus pandemic (COVID-19); Civil Procedural Law in Portugal.

\section{INTRODUÇÃO}

A entrada em vigor da Lei 1-A/2020, de 19 de Março $^{2}$ na sequência da chegada a Portugal, em Março de 2020, da pandemia causada pelo coronavírus SARS-CoV-2, veio introduzir alterações de grande relevo no funcionamento da justiça. Entre essas alterações contam-se aquelas relativas a uma nova forma de realização das audiências de julgamento que, neste contexto, passaram a poder ocorrer, como regra, através de meios telemáticos e com os intervenientes em ambientes privados.

Esta alteração considerável, ainda que transitória, da forma de realização das audiências veio levantar inúmeras questões relativas ao respeito por princípios pelos quais, até à data, se pautava a realização das mesmas. Entre estes princípios conta-se a imediação, traduzida na relação (direta) existente entre o tribunal e os meios de prova.

Neste texto, correspondente a uma talk proferida a 6 de Julho 2021 na Universidade Católica Portuguesa ${ }^{3}$, procurar-se-á averiguar em que medida o princípio da imediação foi afetado pelo regime de realização das audiências, vigente em tempos de pandemia.

Para o efeito, o texto será estruturado essencialmente em três partes.

\footnotetext{
${ }^{2}$ Antecedida pelo DL 10-A/2020 de 13 de Março, que foi ratificado pela Lei 1-A/2020, de 19 de Março (art. 1. ${ }^{\circ}$, alínea a).

${ }^{3}$ E que se inseriu no ciclo de talks subordinadas ao tema "Direito em tempos de pandemia", cujas exposições serão em breve objecto de publicação em Portugal num volume com o mesmo nome.
} 
Uma primeira em que se abordará o significado e sentido do princípio da imediação; uma segunda em que se exporá, em traços largos, o regime vigente durante a pandemia no que se refere à forma de realização das audiências de julgamento, e uma terceira em que se aferirá sobre a efetiva violação (ou não) do princípio da imediação. Neste último capítulo confrontar-se-á o princípio da imediação, quer com o regime transitório da pandemia, quer com o eventual regime pós-pandemia resultante de uma proposta de alteração ao actual $\mathrm{CPC}^{4}$.

Por fim, terminar-se-á com uma (muito) breve conclusão.

\section{O PRINCÍPIO DA IMEDIAÇÃO}

\subsection{Significado}

Na sua origem, o princípio da imediação surge integrado num movimento global de natureza filosófica acerca da conceção do processo civil, oriundo da Revolução Francesa, em que, à ideia de um processo secreto, escrito, mediato e de prova tabelada, se contrapõem princípios como a publicidade, a motivação das decisões judiciais, a oralidade e a livre apreciação da prova 5 .

Em Portugal, o sistema processual civil assim concebido foi consagrado no Código de Processo Civil ${ }^{6}$ de 1939 e mantido, no essencial, pela legislação processual posterior até aos dias de hoje.

Na sua especificidade, a imediação traduz uma relação - de natureza imediata - entre quem julga e os meios de prova $^{7}$, sejam estes de natureza pessoal ${ }^{8}$ ou material. Como refere Paulo Dá Mesquita, a imediação, neste sentido, tem a sua raiz e núcleo na relação

\footnotetext{
${ }^{4}$ Pendente de aprovação final na Assembleia de República à data da elaboração deste texto.

${ }^{5}$ FERNANDES, Manuel Domingos. "O novo código de processo civil e o duplo grau de jurisdição da matéria de facto", Julgar online, Julho 2014.

${ }^{6}$ De ora em diante designado apenas por CPC.

${ }^{7}$ Este sentido mais restrito da imediação corresponde ao chamado sentido subjetivo da imediação. Sobre a distinção entre o sentido subjetivo e objetivo da imediação, v. MESQUITA, Paulo Dá. "Alguns sinais sobre tendências actuais do processo penal português - convergências metodológicas sobre o contraditório, a prova, a imediação e a confiança nos juízes", Julgar, n. ${ }^{\circ} 25,2015$, pp. 123 e ss.

${ }^{8}$ VARELA, João de Matos Antunes; BEZERRA, Manuel; NORA, Sampaio e. Manual de processo civil, $2^{\mathrm{a}}$ ed, Coimbra Editora, Coimbra, 1985, p. 657.
} 
bipolar entre o tribunal e a prova"

Estando em causa provas de natureza pessoal, tal significa que o tribunal deve apreciar diretamente o depoimento da testemunha, do perito ou da parte, produzido perante ele oralmente, sem intermediação de qualquer suporte escrito. Neste sentido, a imediação confunde-se, por conseguinte, com a oralidade.

Quando estejam em causa meios de prova de natureza material, a relação direta estabelece-se entre o tribunal e a coisa, documento ou lugar enquanto meio de prova, como acontece, por exemplo, no caso da inspeção judicial sobre as coisas.

Num sentido mais amplo, a imediação abrange não apenas aquela relação entre o tribunal e a prova, mas também a ideia de que as fontes de prova pessoais “(...) devem estar na relação mais direta possível com os factos a provar"10.

Como tal, constituem manifestações práticas/consequências/reflexos do princípio da imediação no nosso processo civil ${ }^{11}$ :

(i) por uma parte, "que os atos de produção da prova constituenda tenham lugar perante o tribunal, ao qual compete apreciar a prova e pronunciar-se, consequentemente, sobre os factos provados e não provados";

(ii) por outra parte, que "quando esteja disponível uma fonte de prova que implique menos ilações no iter probatório, a ela se deve recorrer, em vez de a uma outra mais distante do facto fundamental a provar. Assim, por exemplo, não está excluída a inquirição da chamada "testemunha de ouvir dizer", mas o depoimento daquela de quemela ouviu o relato dos factos a provar tem maior valor probatório".

Não obstante os diversos sentidos possíveis da imediação, importa considerar para efeitos deste texto e do relevo que tal princípio possa ter em tempos de pandemia, o respetivo sentido subjetivo enquanto referente às provas pessoais, remetendo-nos, por conseguinte, no essencial, para o princípio da oralidade.

Muito embora, para este efeito, o princípio da imediação e o princípio da oralidade se confundam pelo facto de ambos traduzirem uma determinada forma de produção dos

\footnotetext{
${ }^{9}$ MESQUITA, Paulo Dá. "Alguns sinais sobre tendências actuais do processo penal português - convergências metodológicas sobre o contraditório, a prova, a imediação e a confiança nos juízes”, Julgar, n. ${ }^{\circ} 25,2015$, p. 125.

${ }^{10}$ Sentido objetivo da imediação. v. FREITAS, Lebre de. Introdução ao processo civil, $4^{\mathrm{a}}$ ed., Gestlegal, Coimbra, 2017, p. 195. No mesmo sentido, MARQUES, J.P. Remédio, Acção Declarativa à Luz do Código Revisto, Coimbra Editora, Coimbra, 2007, pp. 392 e 393.

${ }^{11}$ FREITAS, Lebre de. Introdução ao processo civil, $4^{\mathrm{a}}$ ed., Gestlegal, Coimbra, 2017, pp. 195 a 197.
} 
meios de prova pessoais, não pode deixar de referir-se que, noutros domínios, não existe equivalência absoluta entre ambos.

A oralidade é, por uma parte, mais lata do que a imediação e, por outra, mais restrita.

A maior abrangência da oralidade decorre do facto de esta constituir a forma padrão da realização de diversos atos processuais ao longo de todo o processo, para além dos atos de produção da prova. Assim acontece com os atos de saneamento e condensação do processo realizados em audiência prévia.

Mas, por outra parte, a imediação no seu sentido amplo é muito mais abrangente do que a oralidade, estendendo-se à relação direta do tribunal também com as provas materiais (para além das pessoais) e à relação entre os factos e as fontes de prova a que otribunal recorre (sentido objetivo da imediação).

Para além da oralidade, outros princípios não confundíveis com a imediação gravitam na órbita deste, em ordem a assegurar a respetiva eficácia ${ }^{12}$ :

Assim acontece com a concentração que, em ordem a evitar a dispersão dos actos de instrução ao longo do tempo, determina que estes deverão, tendencialmente, ter lugar na mesma audiência (arts. $604 .^{\circ}$, n. $^{\circ} 3 ; 456 .^{\circ}$, n. $^{\circ} 1$ e $500 .^{\circ}$, do CPC); com o princípio da continuidade da audiência nos termos do qual as interrupções necessárias deverão durar o mínimo de tempo possível (art. 606. ${ }^{\circ}$, n. ${ }^{\circ}$ s 2 e 3, do CPC); com o princípio da publicidade (art. 606. ${ }^{\circ}$, n. ${ }^{\circ}$ 1, do CPC) e com o princípio da plenitude da assistência do juiz (art. 605. ${ }^{\circ}$, do CPC) segundo o qual a produção da prova deve decorrer perante o tribunal que irá proferir a decisão ${ }^{13}$.

\subsection{Fundamento}

\footnotetext{
12 PISSARRA, Nuno Andrade. "Audiências judiciais por videoconferência no processo civil”, Revista de Direito e Estudos Sociais, ano LXI, 2020, p. 174.

${ }^{13}$ Nesta matéria, a doutrina apresenta algumas diferenças no enquadramento e relação dos diversos princípios entre si. SOUSA, Miguel Teixeira de. Introdução ao Processo Civil, Lex, Lisboa, 2000, p. 65, considera que a imediação é apenas corolário da oralidade, FREITAS, Lebre de. Introdução ao processo civil, $4^{\mathrm{a}}$ ed., Gestlegal, Coimbra, 2017, pp. 197 e 198 considera que a oralidade e concentração são instrumentais relativamente à imediação, SOUSA, Luís Filipe Pires de. O sentido útil do princípio da imediação, 2020, disponível

em: https://www.academia.edu/43470477/O_SENTIDO_ÚTIL_DO_PRINCÍPIO_DA_IMEDIAÇÃO._NOTAS _A_PROPÓSITO_DO_ARTIGO_6o-A_DA_LEI, p. 7, conclui que a imediação é instrumental do contraditório e da igualdade das partes.
} 
A principal razão de ser do princípio da imediação reside na garantia de que ao julgador são conferidos elementos de prova mais verdadeiros e fiáveis, no sentido de fazer atuar de forma eficaz o princípio da livre apreciação da prova (art. $607 .^{\circ}$, n. $^{\circ} 5$, do CPC). A partir das impressões colhidas pelo tribunal na produção da prova e de acordo com as máximas da experiência, o juiz decide de acordo com a livre convicção gerada no seu espírito.

A apreciação da prova de acordo com a livre convicção do julgador implica que este tenha uma intervenção pessoal e direta na produção da prova, formando a partir desta a sua perceção sobre a veracidade ou falsidade dos factos. E apesar de estas perceções serem subjetivas e assentes numa convicção pessoal do juiz, o dever de fundamentação permite, pelo menos, objetivar o iter processual lógico-racional que terá estado na base daquela convicção, assim tornando patente aos destinatários da decisão as razões que lhe estão subjacentes.

O contacto direto do juiz com os meios de prova tem a vantagem de permitir evitar, por um lado, a mediação de outros elementos que podem reduzir uma perceção mais límpida dos meios de prova. Só assim, num certo sentido, se pode afirmar que a convicção formada pelo julgador será verdadeiramente livre.

Por outro lado, no caso das provas pessoais, muito do que através do depoimento se transmite não resulta apenas da comunicação oral e que eventualmente transitaria intacta para o depoimento escrito, mas sobretudo de uma série de outros elementos não verbais e que acabam por poder ser determinantes para o julgador formar a sua livre convicção. Assim acontece, nomeadamente, com as diferentes reações do depoente perante a pergunta que lhe é feita, as eventuais hesitações na resposta, o tom de voz, a atitude nervosa, todo o tipo de linguagem gestual ou mimica, a alteração da cor da face (rubor, palidez, etc) ${ }^{14}$.

Como expressivamente refere Nuno Andrade Pissarra, "[p]orque um depoimento é muito mais do que falas, o juiz deve ser muito mais do que um ouvidor: deve ser um perspicaz observador" 15 .

\footnotetext{
14 SOUSA, Luís Filipe Pires de. O sentido útil do princípio da imediação, 2020, disponível em: https://www.academia.edu/43470477/O_SENTIDO_ÚTIL_DO_PRINCÍPIO_DA_IMEDIAÇÃO._NOTAS_ A_PROPÓSITO_DO_ARTIGO_6o-A_DA_LEI, p. 9.

${ }^{15}$ PISSARRA, Nuno Andrade. "Audiências judiciais por videoconferência no processo civil", Revista de Direito e Estudos Sociais, ano LXI, 2020, p. 172.
} 
A importância da imediação/oralidade é, aliás, patente em diversa jurisprudência. A título de exemplo, pela sua relevância, cita-se o Acórdão de Uniformização deJurisprudência 5/2008, de 11.12.2008 (Santos Cabral) in www.dgsi.pt:

Sem dúvida que a imediação torna possível, na apreciação das provas, a formaçãode um juízo insubstituível sobre a credibilidade da prova; das razões que se podemobservar, no exame direto da prova, para acreditar, ou não acreditar, na mesma. Significa o exposto que a imediação é o meio pelo qual o tribunal realiza um ato de credibilização sustentada sobre determinados meios de prova em relação a outros. Exemplifica-se o exposto recorrendo ao caso do testemunho que parece mais dignode crédito do que um outro pela perceção direta imediata do seu relato e das circunstâncias em que o mesmo se desenrolou: - terá sido mais categórico, eventualmente mais seguro; terá recorrido menos vezes à aquiescência tácita de terceiro; ter-se-á expressado em termos mais correntes e mais próprios da sua condição social o que induziu o tribunal a pensar que o seu testemunho era mais fidedigno e menos passível de preparação prévia; suportou com maior à vontade oexercício do contraditório.

Todas estas, que são razões que servem para acreditar em determinadas provas, e não acreditar noutras, sem dúvida que só são suscetíveis de ser apreciadas diretamente pela pessoa que as avalia - o juiz de julgamento em primeira instância

- e a possibilidade de admitir que tais circunstâncias possam ser aferidas somente com recurso a um escrito - a denominada transcrição - produz uma evidente dificuldade pela ausência, ou diminuta qualidade de informação carreada para o tribunal, suscetível de o informar sobre as razões da atribuição de credibilidade. (...)

A opção por dar fé a um meio de prova sobre outro é seleção que se deve realizar com apelo à imediação já que não pode ser feita de outra forma sem cair em decisõesarbitrárias, pois só a presença direta perante aquele que decide permite aplicar claramente os critérios que permitem optar no caso concreto por uma prova A ou B.

Igualmente claro é o Acórdão do TRG de 20/3/2017 (Jorge Bispo), in www.dgsi.pt:

A imediação, que se traduz no contacto entre o juiz e os diversos meios de prova, confere ao julgador em primeira instância certos meios de apreciação da prova pessoal de que o tribunal de recurso não dispõe.

É essencialmente a esse julgador que compete apreciar a credibilidade das declarações e depoimentos, com fundamento no seu conhecimento das reações humanas, atendendo a uma vasta multiplicidade de fatores que só são apreensíveismediante o contacto direto com os depoentes na audiência: as razões de ciência, a espontaneidade, a linguagem (verbal e não verbal), as hesitações, o tom de voz, ascontradições, etc.

As razões pelas quais se confere credibilidade a determinadas provas e não a outrasdependem desse juízo de valoração realizado pelo juiz da primeira instância, com base na imediação e na oralidade, ainda que condicionado pela aplicação das regrasda experiência comum.

Apesar de, em tese, todos estes elementos de comunicação não verbal poderem ser 
relevantes para a formação da livre convicção do julgador, Pires de Sousa ${ }^{16}$ chama a atenção para os perigos da imediação enquanto potenciadora da valoração dessa sinalética, frequentemente assente em estereótipos e mitos errados relativamente à deteção da mentira. Tais mitos assentariam na ideia de que o depoente "que mente está sob pressão emocional, deixando escapar indicadores do seu sofrimento interno através de canais de que não está ciente nem controla" 17 .

Assim, por exemplo, segundo o Autor citado, existe a ideia de que a testemunha que mente apresenta um contacto visual com o inquiridor maior, mais intenso e não natural como forma de controlo do seu interlocutor, o que, naturalmente, poderá não corresponder à realidade, já que tal difere da forma de mentir de cada pessoa em particular, para além de que o comportamento nervoso pode também ser observado em pessoas que estão a falar verdade. "Não há comportamentos não verbais que estejam presentes em todos os mentirosos e ausentes em todas as pessoas que dizem a verdade. Não há comportamentos não verbais que sejam indicativos do engano, como o nariz de Pinóquio." 18

Com efeito, muitos dos significados atribuídos a indicadores não verbais não assentam em bases científicas e sim meramente empíricas, para além de que a preparação do julgador para os avaliar no caso concreto nem sempre é consistente ${ }^{19}$, o que faz Pires de Sousa concluir que "a presença física da testemunha perante o juiz, afinal, não é assimtão essencial para efeitos de valoração dessa prova" ${ }^{20}$.

Não obstante a pertinente chamada de atenção de Pires de Sousa, não pode deixar de

\footnotetext{
${ }^{16}$ SOUSA, Luís Filipe Pires de. O sentido útil do princípio da imediação, 2020, disponível em: https://www.academia.edu/43470477/O_SENTIDO_ÚTIL_DO_PRINCÍPIO_DA_IMEDIAÇÃO._NOTAS_ A_PROPÓSITO_DO_ARTIGO_6o-A_DA_LEI, pp. 10 e 11 e SOUSA, Luís Filipe Pires de, "Julgamento presencial versus julgamento com telepresença. A pandemia e o futuro", Julgar, n. ${ }^{\circ} 44,2021$, Coimbra, Almedina, pp. 15 e ss.

${ }^{17}$ SOUSA, Luís Filipe Pires de. "Julgamento presencial versus julgamento com telepresença. A pandemia e o futuro", Julgar, n. ${ }^{\circ}$ 44, 2021, Coimbra, Almedina, p. 16.

${ }^{18}$ AAVV, "The Analysis of Nonverbal Communication: The Dangers of Pseudoscience in Security and Justice Contexts", in Anuario de Psicologia Jurídica, 2019, https://doi.org/10.5093/apj2019a9, referido e traduzido por SOUSA, Luís Filipe Pires de, "Julgamento presencial versus julgamento com telepresença. A pandemia e o futuro", Julgar, n. ${ }^{\circ}$ 44, 2021, Coimbra, Almedina, p. 14. No mesmo sentido, MESQUITA, Paulo Dá, "Alguns sinais sobre tendências actuais do processo penal português - convergências metodológicas sobre o contraditório, a prova, a imediação e a confiança nos juízes", Julgar, n. ${ }^{\circ}$ 25, 2015, p. 133.

19 SOUSA, Luís Filipe Pires de. O sentido útil do princípio da imediação, 2020, disponível em: https://www.academia.edu/43470477/O_SENTIDO_ÚTIL_DO_PRINCÍPIO_DA_IMEDIAÇÃO._NOTAS_ A_PROPÓSITO_DO_ARTIGO_6o-A_DA_LEI, pp. 15 e 16.

${ }^{20}$ SOUSA, Luís Filipe Pires de. O sentido útil do princípio da imediação, 2020, disponível em: https://www.academia.edu/43470477/O_SENTIDO_ÚTIL_DO_PRINCÍPIO_DA_IMEDIAÇÃO._NOTAS_ A_PROPÓSITO_DO_ARTIGO_6o-A_DA_LEI, pp. 15 e 16.
} 
atentar-se na importância, ainda que complementar, dos elementos que a comunicação não verbal transmite, razão pela qual o princípio da imediação continua a constituir a regra no nosso sistema processual.

\subsection{O registo da prova e a reapreciação da matéria de facto em segunda instância}

No sistema jurídico português, a oralidade/imediação foi muitas vezes confundida com a ausência de registo da prova produzida em audiência ${ }^{21}$. Daí que, até 1995, a oralidade/imediação tenha sido sempre entendida num sentido puro, ou seja, desacompanhada de qualquer registo de prova, o que, aliás, foi objeto de diversas contestações.

Já no I Congresso Nacional dos Advogados Portugueses, que teve lugar em 1972, Alexandre Pessoa $\mathrm{Vaz}^{22}$ havia apresentado uma comunicação intitulada "o tríplice ideal da justiça célere, económica e segura ao alcance do legislador processual moderno", com o subtítulo "sugestões para uma reforma judiciária que elimine a curto prazo o nossoatual e vicioso sistema de oralidade pura", sendo uma das finalidades dessa comunicação precisamente a defesa de uma oralidade mitigada:

(...), demonstrar que o sistema de 'oralidade pura', em matéria de instrução probatória, que ainda domina a nossa legislação processual civil, e que foi entre nósintroduzido, como é de todos sabido, passa de meio século, pelo Dec. 21694, de 29de Setembro de 1932, constitui um sistema de grave carência de algumas das 'garantias judiciárias fundamentais do cidadão' (designadamente, a documentaçãoda prova, a motivação das sentenças de facto, o recurso para um Tribunal hierarquicamente superior dessas mesma sentenças, e até, em alguma medida, o princípio primordial da publicidade): sistema de tal forma 'precário e aberrante' neste importante domínio das garantias judiciárias, em face da generalidade das leis processuais estrangeiras de todos os países civilizados, e da nossa própria tradição histórico-legislativa, que depois da Revolução Francesa e ressalvadas que sejam algumas aflorações de caráter marcadamente autoritário, hoje, em grande parte, ultrapassadas), não tem qualquer paralelo em nenhum dos países mais progressivos do Mundo contemporâneo - quer da vasta e diversificada área Ocidental, quer mesmo da também ampla zona do bloco Socialista.

\footnotetext{
${ }^{21}$ FERNANDES, Manuel Domingos. "O novo código de processo civil e o duplo grau de jurisdição da matéria de facto", Julgar online, Julho 2014.

${ }^{22}$ VAZ, Alexandre Pessoa. Os grandes paradoxos da política judiciária nos últimos cinquenta anos, in Da Crise da Justiça em Portugal, s/d, disponível em: https://portal.oa.pt/upl/\%7B41a8971d-e10e-4a4a-b136cc5dcc624371\%7D.pd, pp. 626 e 627.
} 
Para compensar a perda de garantias para as partes resultante da não documentação da prova e consequente impossibilidade de revisão da decisão por tribunais superiores, o sistema vigente era o do julgamento colegial em primeira instância. Ou seja, um sistema de oralidade pura, associado à colegialidade do julgamento.

A partir de 97, com a alteração do Decreto-Lei n ${ }^{\circ} 39 / 95$, de 15 de Fevereiro ao CPC, a par da documentação e registo da prova, a Relação passou a poder alterar o julgamento da matéria de facto efetuado pela primeira instância, de acordo com a sua livre convicção. Como se pode ler no preâmbulo daquele Decreto-Lei, passou a existir, como consequência, "um verdadeiro e efetivo $2^{\circ}$ grau de jurisdição da matéria de facto, facultando às partes na causa uma maior e mais real possibilidade de reação contra eventuais - e seguramente excecionais - erros do julgador na livre apreciação da prova (...)".

Todavia, a possibilidade de sindicância do julgamento da matéria de facto pelas Relações acabou por introduzir uma restrição inevitável ao princípio da imediação, uma vez que passou a ser possível ao tribunal julgar a matéria de facto sem contacto direto com as provas pessoais.

Como escreve Abrantes Geraldes ${ }^{23}$ :

(...) existem aspetos comportamentais ou reações dos depoentes que apenas são percecionados, apreendidos, interiorizados e valorados por quem os presencia e quejamais podem ficar gravados ou registados para aproveitamento posterior por outrotribunal que vá reapreciar o modo como no primeiro se formou a convicção do julgador. O sistema não garante de forma tão perfeita quanto a que é possível na $1^{\text {a } i n s t a ̂ n c i a ~ a ~ p e r c e c ̧ a ̃ o ~ d o ~}$ entusiamo, das hesitações, do nervosismo, das reticências, das insinuações, da excessiva segurança ou da aparente imprecisão, em suma, de todos os fatores coligidos pela psicologia judiciária e de onde é legítimo ao tribunal retirar argumentos que permitam, com razoável segurança, credibilizar determinadainformação ou deixar de lhe atribuir qualquer relevo.

De igual forma se pronuncia a jurisprudência sobre esta matéria.

Segundo o Acórdão do STJ de 21/5/2009 (Salazar Casanova), in www.dgsi.pt:

É inevitável reconhecer que, com o sistema assim introduzido [de duplo grau de julgamento da matéria de facto], a lei fez prevalecer a garantia do segundo grau dejurisdição sobre as vantagens da imediação na apreciação da prova testemunhal; e que aceitou que, para a $2^{\mathrm{a}}$ Instância, esta falta de imediação não prejudicava a efetividade do princípio da livre apreciação da prova.

Também o Acórdão do STJ de 1/6/2010 (Salazar Casanova), in www.dgsi.pt, torna consciente a restrição à imediação, chamando, no entanto, a atenção para que tal

\footnotetext{
${ }^{23}$ GERALDES, Abrantes. Recursos no NCPC, $2^{\mathrm{a}}$ ed., Coimbra, Almedina, 2013, p. 234.
} 
circunstância, por si só, não constitui motivo que impeça a Relação de formar a sua convicção sobre os meios de prova registados (maxime, os depoimentos das testemunhas) ${ }^{24}$ :

I - Impugnada a matéria de facto com observância pelo recorrente das regras processuais que possibilitem ao Tribunal da Relação a reapreciação da prova, não pode este Tribunal deixar de proceder à reapreciação da prova conforme decorre dodisposto no art. $712 .^{\circ}$, n. $^{\circ} 2$, do CPC.

II - Se o tribunal de 1 . $^{\mathrm{a}}$ instância tiver, na motivação da matéria de facto, evidenciado aspetos factuais atinentes a um juízo de imediação que o registo magnético não permite captar ou se esse juízo de imediação se evidenciar em funçãodo próprio material probatório que influenciou a decisão de facto (v.g. inspeção aolocal, prova pericial), o Tribunal da Relação, após audição do registo magnético, não deixará de ponderar, no seu juízo prudencial, a relevância de tais aspetos de facto integrados no contexto geral de avaliação da prova produzida e, assim sendo, de acordo com a sua convicção (art. 655. ${ }^{\circ}$ do $\mathrm{CPC}$ ), confirmará ou não confirmaráa decisão de facto.

Para clarificar as dúvidas sobre a amplitude da possível alteração da matéria de facto pelas Relações, o legislador de 2013 reforçou e ampliou os poderes da Relação no julgamento do recurso da matéria de facto, impondo-lhe (art. 662. ${ }^{\circ}$, do CPC) formar a sua própria convicção sobre a matéria de facto impugnada, sem se limitar à análise da congruência entre a fundamentação e a decisão ou à correção de erros manifestos e grosseiros. Mas, em simultâneo, o novo CPC tornou mais fácil ultrapassar limitações resultantes da falta de imediação através da ampliação da possibilidade de renovação da prova e da permissão de produção de novos meios de prova. ${ }^{25}$ Ainda assim, indiretamente, continuou-se a assumir que a vantagem da reapreciação ultrapassava as desvantagens dafalta de imediação.

Em suma, a possibilidade de os tribunais de segunda instância reapreciarem o julgamento da matéria de facto com base no registo gravado das provas pessoais revela que, apesar de regra, a imediação não constitui um absoluto no nosso Processo Civil, cedendo, em maior ou menor medida em face de outros princípios igualmente relevantes, numa base de proporcionalidade.

\section{O REGIME TRANSITÓRIO DA PANDEMIA: A LEI N. ${ }^{\circ}$ 1-A/2020, DE 19 DE}

\footnotetext{
${ }^{24}$ BELEZA, Maria dos Prazeres. "Julgamento de Facto em $1^{\text {a }}$ e $2^{\text {a }}$ Instâncias", Jurismat, Portimão, 2020, n. ${ }^{\text {o }}$ 12, pp. 203 a 220.

25 Sobre este reforço do princípio da imediação pelo CPC 2013 através do reforço dos poderes da Relação sobre a produção de meios de prova, v. ALEXANDRE, Isabel. "A fase da instrução e os novos meios de prova no Código de Processo Civil de 2013”, Revista do Ministério Público, 134, Abril/Junho 2013, pp. 25 e 26.
} 


\section{MARÇO ${ }^{26}$}

Através da Lei n. ${ }^{\circ}$ 1-A/2020, de 19 de Março foram instituídas um conjunto de "medidas excecionais e temporárias de resposta à situação epidemiológica provocada pelo coronavírus SARS-CoV-2", com o objetivo de minimizar o impacto da pandemia na administração da justiça. Entre estas medidas, contam-se algumas providências relativas a processos judiciais pendentes referentes, designadamente, aos prazos em curso para a prática de actos processuais e à forma de realização das audiências.

Daquelas medidas sublinhar-se-ão apenas as relativas à forma de realização da audiência de discussão e julgamento, momento por excelência destinado à produção das provas de cariz pessoal e em que, por conseguinte, se concretiza o princípio da imediação, objecto do nosso estudo.

Ao longo das diferentes fases de evolução da pandemia, evoluiu também a forma regra de realização das audiências de discussão e julgamento, que oscilou entre a realização presencial e a realização através de meios telemáticos.

Assim, nas fases de maior incidência da doença, optou-se, como regra, pelo recurso a sistemas de videoconferência para a realização das audiências, o mesmo tendo acontecido, em geral, nos vários países da União Europeia. Ao invés, nas fases de abrandamento do ritmo de transmissão da Covid-19, foi retomada a regra da realização presencial daquelas audiências, sem prejuízo da manutenção de algumas excepções que visavam acautelar certas situações de risco.

Assim, na sua primeira versão correspondente ao início da pandemia, a Lei n. $^{\circ} 1$ A/2020, de 19/3 dispôs, no seu art. $7^{\circ}$, que a todos os processos judiciais pendentes se aplicaria a regra do regime das férias judiciais. Ou seja, no caso das audiências de discussão e julgamento, estas não se realizariam, salva a possibilidade de realização das mesmas através de meios de comunicação à distância adequados.

Art. 7. ${ }^{\circ}$

(...)

8 - Sempre que tecnicamente viável, é admitida a prática de quaisquer atos processuais e procedimentais através de meios de comunicação à distância adequados, designadamente por teleconferência ou videochamada.

9 - No âmbito do presente artigo, realizam-se apenas presencialmente

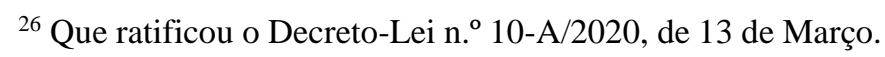


os atos e diligências urgentes em que estejam em causa direitos fundamentais, nomeadamente diligências processuais relativas a menores em risco ou a processos tutelares educativos de natureza urgente, diligências e julgamentos de arguidos presos, desde que a sua realização não implique a presença de um número de pessoas superior ao previsto pelas recomendações das autoridades de saúde e de acordo com as orientações fixadas pelos conselhos superiores competentes.

A primeira alteração à referida lei surgiu menos de um mês depois, através das Leis n. ${ }^{\circ}$ 4-A e B/2020, de 06/04, que vieram esclarecer alguns aspetos que não resultaram claros da primeira versão da Lei. No que se refere à forma de realização das audiências ( $\operatorname{art.} 7^{\circ}$ ), no entanto, e uma vez que se estava ainda longe do fim da primeira vaga da pandemia, mantevese, no essencial, a regra da realização das audiências através de meios telemáticos, distinguindo-se, no entanto, com ligeiras diferenças, a previsão quanto aos processos urgentes e não urgentes. Nos processos não urgentes, a realização das audiências à distância dependeria do acordo das partes enquanto que nos processos não urgentes a realização das audiências à distância seria também a regra mas sem necessidade de acordo das partes para o efeito.

Art. 7. ${ }^{\circ}$

(...)

5 - O disposto no n. ${ }^{\circ} 1$ [suspensão dos prazos para a prática dos actos] não obsta:

a) À tramitação dos processos e à prática de atos presenciais e não presenciais não urgentes quando todas as partes entendam ter condições para assegurar a sua prática através das plataformas informáticas que possibilitam a sua realização por via eletrónica ou através de meios de comunicação à distância adequados, designadamente teleconferência, videochamada ou outro equivalente;

b) A que seja proferida decisão final nos processos em relação aos quais o tribunal e demais entidades entendam não ser necessária a realização de novas diligências.

(...)

7 - Os processos urgentes continuam a ser tramitados, sem suspensão ou interrupção de prazos, atos ou diligências, observando-se quanto a estes o seguinte:

a) Nas diligências que requeiram a presença física das partes, dos seus mandatários ou de outros intervenientes processuais, a prática de quaisquer atos processuais e procedimentais realiza-se através de meios de comunicação à distância adequados, designadamente teleconferência, videochamada ou outro equivalente;

b) Quando não for possível a realização das diligências que requeiram a presença física das partes, dos seus mandatários ou de outros intervenientesprocessuais, nos termos da alínea anterior, e esteja em causa a vida, a integridade física, a saúde mental, a liberdade ou a subsistência imediata dosintervenientes, pode realizar-se presencialmente a diligência desde que a mesma não implique a presença de um número de pessoas 
superior ao previsto pelas recomendações das autoridades de saúde e de acordo com asorientações fixadas pelos conselhos superiores competentes;

c) Caso não seja possível, nem adequado, assegurar a prática de atos ou a realização de diligências nos termos previstos nas alíneas anteriores, aplica-se também a esses processos o regime de suspensão referido no n. ${ }^{\circ}$ 1.

Em 29 de Maio de 2020, no final da primeira vaga da pandemia, a Lei n. ${ }^{\circ}$ 16/2020,de 29/05 veio aliviar as medidas anteriormente adotadas, através do aditamento do art. $6^{\circ} \mathrm{A}$, que veio a restabelecer a regra da realização presencial das audiências de discussãoe julgamento, ainda que prevendo diversas possibilidades em alternativa:

Art. $6 .^{\circ}-\mathrm{A}$

(...)

2 - As audiências de discussão e julgamento, bem como outras diligências queimportem inquirição de testemunhas, realizam-se:

a) Presencialmente e com a observância do limite máximo de pessoas e demais regras de segurança, de higiene e sanitárias definidas pela Direção-

Geral da Saúde (DGS); ou

b) Através de meios de comunicação à distância adequados, nomeadamente teleconferência, videochamada ou outro equivalente, quando não puderem ser feitas nos termos da alínea anterior e se for possível e adequado,designadamente se não causar prejuízo aos fins da realização da justiça, embora a prestação de declarações do arguido ou de depoimento das testemunhas ou de parte deva sempre ser feita num tribunal, salvo acordo das partes em sentido contrário ou verificando-se uma das situações referidas no n. ${ }^{\circ} 4$.

$3-(\ldots)$

4 - Em qualquer das diligências previstas nos n. 2 e 3, as partes, os seus mandatários ou outros intervenientes processuais que, comprovadamente, sejam maiores de 70 anos, imunodeprimidos ou portadores de doença crónica que, de acordo com as orientações da autoridade de saúde, devam ser considerados de risco, não têm obrigatoriedade de se deslocar a um tribunal, devendo, em caso de efetivação do direito de não deslocação, a respetiva inquirição ou acompanhamento da diligência realizar-se através de meios de comunicação à distância adequados, designadamente teleconferência, videochamada ou outro equivalente, a partir do seu domicílio legal ou profissional.

Com o início de uma nova fase de agravamento da pandemia no início de 2021 surgiu também uma nova alteração à Lei no que respeita à forma de realização das audiências de discussão e julgamento. Com este intuito, veio a Lei n. ${ }^{\circ}$ 4-B/2021, de 01/02alterar novamente a Lei n. ${ }^{\circ}$ 1-A/2020, de 19 de Março, no que a esta questão concerne, através da revogação do art $6 .^{\circ} \mathrm{A}$ e da introdução do art. $6{ }^{\circ} \mathrm{B}$, que restabeleceu a regra darealização das audiências de discussão e julgamento através de meios digitais, ainda que com algumas nuances consoante esteja em causa um processo urgente ou não urgente: 
Art. $6^{\circ} \mathrm{B}(\ldots)$

6 - O disposto no n. 1 [da suspensão dos prazos e diligências] não obsta:

a) À tramitação nos tribunais superiores de processos não urgentes, sem prejuízo do cumprimento do disposto na alínea c) quando estiver em causa arealização de atos presenciais;

b) À tramitação de processos não urgentes, nomeadamente pelas secretariasjudiciais; À prática de atos e à realização de diligências não urgentes quando todasas partes o aceitem e declarem expressamente ter condições para assegurara sua prática através das plataformas informáticas que possibilitam a sua realização por via eletrónica ou através de meios de comunicação à distância adequados, designadamente teleconferência, videochamada ou outro equivalente;

c) A que seja proferida decisão final nos processos e procedimentos em relação aos quais o tribunal e demais entidades referidas no $n .^{\circ} 1$ entendam não ser necessária a realização de novas diligências, caso em que não se suspendem os prazos para interposição de recurso, arguição de nulidades ou requerimento da retificação ou reforma da decisão.

(...)

7 - Os processos, atos e diligências considerados urgentes por lei ou por decisão da autoridade judicial continuam a ser tramitados, sem suspensão ou interrupçãode prazos, atos ou diligências, observando-se quanto a estes o seguinte:

a) Nas diligências que requeiram a presença física das partes, dos seus mandatários ou de outros intervenientes processuais, a prática de quaisquer atos processuais e procedimentais realiza-se, se não causar prejuízo aos fins da realização da justiça, através de meios de comunicação à distância adequados, designadamente teleconferência, videochamada ou outro equivalente;

b) Quando não for possível a realização das diligências que requeiram a presença física das partes, dos seus mandatários ou de outros intervenientesprocessuais, nos termos da alínea anterior, pode realizar-se presencialmentea diligência, nomeadamente nos termos do $n .^{\circ} 2$ do artigo $82 .^{\circ}$ da Lei n. ${ }^{\circ} 62 / 2013$, de 26 de agosto, competindo ao tribunal assegurar a realização damesma em local que não implique a presença de um número de pessoas superior ao previsto pelas recomendações das autoridades de saúde e de acordo com as orientações fixadas pelos conselhos superiores competentes.

8 - As partes, os seus mandatários ou outros intervenientes processuais que, comprovadamente, sejam maiores de 70 anos, imunodeprimidos ou portadores de doença crónica que, de acordo com as orientações da autoridade de saúde, devam ser considerados de risco, não têm obrigatoriedade de se deslocar a um tribunal, devendo, em caso de efetivação do direito de não deslocação, a respetiva inquirição ou acompanhamento da diligência realizar-se através de meios de comunicação à distância adequados, designadamente teleconferência, videochamada ou outro equivalente, a partir do seu domicílio legal ou profissional.

9 - Em qualquer das diligências previstas na alínea c) do n. ${ }^{\circ} 5$ e na alínea a) do n. ${ }^{\circ}$, a prestação de declarações do arguido e do assistente, bem como o depoimentodas testemunhas ou de parte, devem ser realizadas a partir de um tribunal ou de instalações de edifício público, desde que a mesma não 
implique a presença de umnúmero de pessoas superior ao previsto pelas orientações das autoridades de saúdee de acordo com as orientações fixadas pelos conselhos superiores competentes.

Por último, o fim daquela vaga da pandemia que teve início nos primeiros meses de 2021, deu lugar à alteração preconizada pela Lei n. ${ }^{\circ} 13-B / 2021$, de 05/4, através da qual se revogou o art. $6 .^{\circ} \mathrm{B}$ e se aditou art. $6 .^{\circ} \mathrm{E}$, que restabeleceu a regra da realização presencial das audiências de discussão e julgamento e cuja versão se manteve até à data da elaboração deste texto:

Art. $6^{\circ} \mathrm{E}(\ldots)$

2 - As audiências de discussão e julgamento, bem como outras diligências queimportem inquirição de testemunhas, realizam-se:

a) Presencialmente, nomeadamente nos termos do n. ${ }^{\circ} 2$ do artigo 82. da Lein. ${ }^{\circ} 62 / 2013$, de 26 de agosto, na sua redação atual; ou

b) Sem prejuízo do disposto no n. ${ }^{\circ} 5$, através de meios de comunicação à distância adequados, nomeadamente teleconferência, videochamada ou outro equivalente, quando não puderem ser feitas nos termos da alínea anterior e a sua realização por essa forma não colocar em causa a apreciação e valoração judiciais da prova a produzir nessas diligências, exceto, em processo penal, a prestação de declarações do arguido, do assistente e das partes civis e o depoimento das testemunhas.

3 - Em qualquer caso, compete ao tribunal assegurar a realização dos atosjudiciais com a observância do limite máximo de pessoas e demais regras de segurança, de higiene e sanitárias definidas pela DGS.

4 - Nas demais diligências que requeiram a presença física das partes, dos seus mandatários ou de outros intervenientes processuais, a prática de quaisquer outrosatos processuais e procedimentais realiza-se:

a) Preferencialmente através de meios de comunicação à distância adequados, nomeadamente teleconferência, videochamada ou outro equivalente; ou

b) Quando tal se revelar necessário, presencialmente.

5 - As partes, os seus mandatários ou outros intervenientes processuais que, comprovadamente, sejam maiores de 70 anos, imunodeprimidos ou portadores de doença crónica que, de acordo com as orientações da autoridade de saúde, devam ser considerados de risco, não têm obrigatoriedade de se deslocar a um tribunal, devendo, em caso de efetivação do direito de não deslocação, a respetiva inquirição ou acompanhamento da diligência realizar-se através de meios de comunicação à distância adequados, designadamente teleconferência, videochamada ou outro equivalente, a partir do seu domicílio legal ou profissional.

Em rigor, as possibilidades abertas pelo regime da Lei n. ${ }^{\circ}$ 1-A/2020 não constituíram absoluta novidade relativamente ao regime já existente no CPC, que continha soluções semelhantes. Referimo-nos ao regime do CPC relativo à possibilidade de, desde que residentes fora do concelho em que se encontra sediado o tribunal ou juízo,as testemunhas 
serem ouvidas através de meios telemáticos ${ }^{27}$ (art. 502. ${ }^{\circ}$ ), o mesmo se prevendo relativamente aos peritos quando alguma das partes o requeira ou o juiz o ordene (art. $486 .^{\circ}$ ) e ao depoimento de parte residente fora da comarca ou da respetiva ilha no caso das Regiões Autónomas (art. 456..$^{\circ}$ ), extensível às declarações de parte (art. 466. ${ }^{\circ}$, n. $^{\circ}$ 2). De igual forma, o art. 517. já previa a possibilidade de as testemunhas, mediante acordo das partes, serem inquiridas pelos mandatários judiciais no domicílio profissional de um deles.

As diferenças entre o regime do CPC e o da Lei n. ${ }^{\circ} 1-\mathrm{A} / 2020$, de $19 / 3$ quanto à possibilidade de as provas pessoais não serem produzidas presencialmente em sala de audiência reconduzem-se, no essencial, a dois aspetos.

Em primeiro lugar, o regime existente no CPC destina-se a casos pontuais, como a circunstância de os depoentes residirem em zonas distantes do tribunal onde decorre a audiência, sendo, pelo contrário, o regime da pandemia, no período a que se refere, aplicável, como regra, a todas as audiências de discussão e julgamento. Apesar disso, pode afirmar-se que ambos os regimes acabam por ser regimes de exceção, ainda que emsentidos diferentes.

Para além disso, note-se que o regime transitório da pandemia veio alargar a possibilidade de realização das audiências por teleconferência a um contexto privado, sem exigências de localização física dos intervenientes processuais em qualquer edifício público e sem mesmo qualquer controlo público sobre os depoimentos prestados ${ }^{28}$.

Relevante é o facto de que a existência de um regime processual contido no CPC e já devidamente experimentado podia ter servido de base ao regime especial da Lei 1- A/2020 não tendo sido essa, no entanto, a opção do legislador, o que suscitou diversas críticas nesse sentido. Com efeito, por uma parte, o regime já existente era, naturalmente, mais consistente, por outra, aquela opção legislativa acabou por desencadear uma duplicação desnecessária de regimes, dando origem a dúvidas desnecessárias resultantes da vigência simultânea de ambos.

Neste contexto se compreendem algumas críticas dirigidas à Lei n. ${ }^{\circ}$ 1-A/2020. Em

\footnotetext{
${ }^{27} \mathrm{Ou}$ mesmo através de meios telefónicos quando ocorra "impossibilidade ou grave dificuldade de atempada comparência de quem deva depor na audiência" e haja acordo das partes (art. 520. ${ }^{\circ}$ ).

${ }^{28} \mathrm{Cfr}$. SOUSA, Luís Filipe Pires de. "Julgamento presencial versus julgamento com telepresença. A pandemia e o futuro", Julgar, n. ${ }^{\circ} 44,2021$, Coimbra, Almedina, p. 14 e PISSARRA, Nuno Andrade. "Audiências judiciais por videoconferência no processo civil', Revista de Direito e Estudos Sociais, ano LXI, 2020, pp. 168 e 160. Algumas exceções, no entanto, em que a teleconferência em tempos de pandemia seria realizada num contexto que se aproximava do contexto público, podem encontrar-se por ex. no art. $6^{\circ} \mathrm{B}$, n. ${ }^{\circ} \mathrm{s} 5$, c); 7 , a) e 9 da Lei 1 - A/2020, na versão que the foi conferida pela Lei n. ${ }^{\circ} 4-\mathrm{B} / 2021$, de $1 / 2$.
} 
especial, tais comentários críticos ganharam maior consistência com a alteração à referidaLei introduzida pela Lei n. ${ }^{\circ} 16 / 2020$, de $29 / 05$, a partir da qual se abriu novamente a porta à regra da realização presencial das audiências, mantendo-se, no entanto, a possibilidade de, em algumas circunstâncias, aquelas se poderem continuar a realizar através de videoconferência.

Segundo o comentário crítico de Marco Gonçalves, não fez sentido a prevalência então dada à realização presencial das audiências, devendo ser dada primazia aos meios de comunicação à distância: "[a]demais, sendo o processo judicial tramitado por via eletrónica (art. 132. ${ }^{\circ}$ do CPC) e estando perfeitamente instituída a possibilidade de inquirição através de teleconferência, com respeito pelo princípio da imediação (cfr. os arts. $456 .^{\circ}$ e $486 .^{\circ}$ do CPC), não se percebe por que razão o legislador veio, mesmo assim,insistir na realização generalizada de diligências em moldes presenciais" 29 .

Também Pires de Sousa deixou clara a necessidade de compatibilizar aqueles regimes, chamando, em particular, a atenção para a inconsistência do art. $6 .^{\circ} \mathrm{A}, \mathrm{n} .^{\circ} 2, \mathrm{~b}$ ), na versão que lhe foi dada pela Lei n. ${ }^{\circ} 16 / 2020$, de $29 / 5$, onde se refere a exigência de mesmo em audiências realizadas por meios digitais, o depoimento da testemunha ou da parte "ser sempre feita num tribunal”. Segundo aquele Autor, “(...) do ponto de vista do processo civil, o legislador não atendeu a que, no art. $502^{\circ}$, se permite a inquirição a partirda instalação do município ou freguesia, quando protocolado, ou de outro edifício públicoda área da residência da testemunha" ${ }^{30}$, no sentido de qualquer local que a testemunha sinta que é de referência. Desta inconsistência inexplicável não pode deixar de concluir-se, por conseguinte, que o regime da pandemia afastou aquele regime do $\mathrm{CPC}$.

\section{O PRINCÍPIO DA IMEDIAÇÃO ESTÁ POSTO EM CAUSA?}

\subsection{A imediação e a Lei n. ${ }^{\circ}$ 1-A/2020, de 19/3}

\footnotetext{
${ }^{29}$ GONÇALVES, Marco Carvalho. Atos Processuais e Prazos no âmbito da pandemia da doença Covid-19,

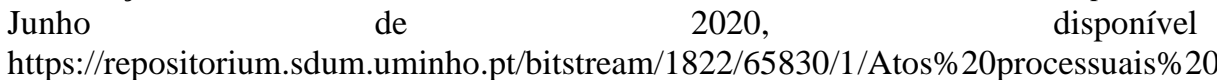
$\% 20$ prazos\%20no\%20âmbito\%20da\%20pandemia\%20da\%20doença\%20Covid-

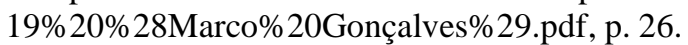

30 SOUSA, Luís Filipe Pires de. O sentido útil do princípio da imediação, 2020, disponível em: https://www.academia.edu/43470477/O_SENTIDO_ÚTIL_DO_PRINCÍPIO_DA_IMEDIAÇÃO.NOTAS_ A_PROPÓSITO_DO_ARTIGO_6o-A_DA_LEI, p. 6.
} 
Como já se deixou claro, a produção das provas pessoais através de meios telemáticos não constitui uma novidade em absoluto, razão pela qual uma eventual violação do princípio da imediação já se colocaria, ainda que em menor dimensão, relativamente ao regime já contido no CPC. E, não obstante, não se entendia existir aí uma violação da imediação.

Como já referia Paulo Dá Mesquita ${ }^{31}$ relativamente ao regime do CPC:

Entre os antigos polos antagónicos, comunicação presencial versus leitura da transcrição do depoimento, apresentam-se, por via das novas tecnologias, outras alternativas em que ressaltam os mediadores digitais. O esquema da imediação jurídico-processual em vigor no sistema legal português pressupõe que o contacto com a fonte de prova integra, além da relação presencialde partilha do espaço, a comunicação à distância através da teleconferência.

A intermediação de meios digitais na prestação de depoimento de testemunhas ou partes, não parece, por isso, afetar o alegado contacto direto do julgador com a prova ${ }^{32}$. Ainda que a realização presencial das audiências pareça garantir a imediação numa maior medida, em rigor tal conclusão é apenas aparente. Contacto direto não equivale necessariamente a contacto presencial.

Visando a imediação facultar ao tribunal elementos de valoração da prova que vão para além da linguagem verbal, não pode deixar de concluir-se que também a videoconferência permite ao juiz captar a maior parte de tais elementos, ainda que não na totalidade. Assim acontece com aspetos como a hesitação na resposta, o nervosismo, a ruborização, o olhar fixo ou distante, entre outros ${ }^{33}$.

E mais. Aplicando o afirmado ao contexto de pandemia, em que a alternativa seriaa realização presencial das audiências de discussão e julgamento com depoentes necessariamente de máscara por razões de saúde pública, poder-se-ia até concluir que tal circunstância seria muito mais violadora do princípio da imediação uma vez que, por detrás

${ }^{31}$ MESQUITA, Paulo Dá. "Alguns sinais sobre tendências actuais do processo penal português convergências metodológicas sobre o contraditório, a prova, a imediação e a confiança nos juízes", Julgar, n. ${ }^{\circ}$ 25, 2015, p. 131. No Processo Penal, a teleconferência constitui um dos mecanismosprevistos na lei de proteção de testemunhas (arts. $2 .^{\circ}$, c), $5 .^{\circ}$ e $6 .^{\circ}$ da Lei 93/99), prescrevendo-seexpressamente que a mesma satisfaz o princípio da imediação "para todos os efeitos" (art. 15..$^{\circ}$.

${ }^{32}$ De diferente opinião é PISSARRA, Nuno Andrade. "Audiências judiciais por videoconferência no processo civil”, Revista de Direito e Estudos Sociais, ano LXI, 2020, pp. 174 e ss.

${ }^{33}$ Por maioria de razão, quem considere que os elementos não verbais transmitidos pelo depoente são enganadores e irrelevantes para a conclusão sobre a veracidade do depoimento, considerará igualmente quea presença física do depoente não será essencial. Assim, SOUSA, Luís Filipe Pires de. "Julgamento presencial versus julgamento com telepresença. A pandemia e o futuro", Julgar, n. ${ }^{\circ} 44,2021$, Coimbra, Almedina, pp. 21 e 22 . 
da máscara, se perdem muitos dos elementos relevantes da linguagem não verbal.Assim o conclui Marco Carvalho Gonçalves ${ }^{34}$, ao afirmar:

Nem se diga, por outro lado, que a generalização da realização das audiências finais ou das diligências que importem a inquirição de testemunhas de forma presencial tem em vista garantir a observância do princípio da imediação e/ou salvaguardar a formação da convicção do julgador quanto ao valor da provaproduzida.

É que, não se pode ignorar que a produção de um depoimento por alguém cuja facese encontra parcialmente oculta, por razões de saúde pública, não deixa de constituirum entrave à captação, pelo julgador, das expressões faciais de quem depõe, o queassume particular relevância no momento da valoração da prova e da motivação dadecisão judicial (...).

Não obstante, não pode deixar de salientar-se o facto de que a intermediação dos meios digitais não permite tudo o que seria possível através da presencialidade. Assim acontece, por exemplo, com a maior dificuldade de confrontação dos depoentes com certos meios de prova ou com a acareação de testemunhas. Daí que, no entender de Pires de Sousa, a Lei n. ${ }^{o}$ 1-A/2020, de 19/3 (na sequência da alteração pela Lei 4-B/2021, de 01/02), ao fazer depender a possibilidade de realização da audiência por meios telemáticos de esta "não causar prejuízo aos fins da realização da justiça”, criou uma cláusula de salvaguarda que visou precisamente acautelar casos como os descritos ${ }^{35}$ :

O que a cláusula [de salvaguarda para a realização presencial] reclama é que, casoa caso, em função das particularidades da prova do litígio, o juiz aquilate se a presença telemática da testemunha colide com as necessidades concretas de atuaçãodo princípio da imediação. Ou seja, as particularidades da prova no caso concreto podem justificar uma atuação musculada dos princípios da imediação e da oralidade, preconizando que a testemunha deponha presencialmente em tribunal. (...). Será, por exemplo, o caso de se assegurar a realização de uma acareação, de, nos termos do Art. $607^{\circ}, \mathrm{n}^{\circ}$, o juiz entender reabrir a audiência para inquirição presencial de uma testemunha ou de ser tecnicamente inviável o confronto de testemunha com documento em sede de audiência telemática. Esta aferição pode quedar-se pela premência da atuação do princípio da imediação no caso ou ser mais exigente, atendendo aos direitos e valores em discussão no processo, nomeadamente aquilatando se no processo está em causa a vida, integridade física,saúde mental, habitação, liberdade ou subsistências das partes.

\footnotetext{
${ }^{34}$ GONÇALVES, Marco Carvalho. Atos Processuais e Prazos no âmbito da pandemia da doença Covid-19, Junho de 2020, disponível em: https://repositorium.sdum.uminho.pt/bitstream/1822/65830/1/Atos\%20processuais\%20e\%20prazos\%20no\% 20 âmbito $\% 20$ da\% 20 pandemia\%20da\%20doença\%20Covid-19\%20\%28Marco\%20Gonçalves\%29.pdf, p. 26

35 SOUSA, Luís Filipe Pires de. O sentido útil do princípio da imediação, 2020, disponível em: https://www.academia.edu/43470477/O_SENTIDO_ÚTIL_DO_PRINCÍPIO_DA_IMEDIAÇÃO._NOTAS_ A_PROPÓSITO_DO_ARTIGO_6o-A_DA_LEI, p. 4.
} 
Mas ainda que não viole a imediação e que acarrete até certos benefícios ${ }^{36}$, a videoconferência, sobretudo em contextos de audiência em ambientes privados, poderá naturalmente afetar outros princípios e garantias processuais que sairão necessariamentee mais fragilizados desta pandemia.

Não há como contestar o facto de que o depoimento por videoconferência acaba por provocar uma sensação de distância entre depoentes e tribunal, agravada ainda mais pela possibilidade de tal ocorrer em ambientes privados.

E claro que tais circunstâncias podem afetar aspetos como a autenticidade e genuidade do depoimento, a formalidade e solenidade do mesmo, a publicidade ${ }^{37}$, o princípio da proximidade tribunais/populações ${ }^{38}$, etc. Com efeito, depoimentos através de meios digitais são necessariamente mais permeáveis à possibilidade de fraudes à identidade do depoente, interferência de terceiros nos testemunhos, pré-preparação do depoimento para além dos limites admitidos pelo art. $4611^{\circ}, \mathrm{n} .^{\circ} 2$, etc.

Referindo-se ao depoimento em ambientes privados, conclui Pires de Sousa ${ }^{39}$ que:

O principal problema que a inquirição de testemunha, a partir do domicíliopessoal, profissional ou outro local, suscita é o de o tribunal se assegurar 'pelos meios possíveis, da autenticidade e plena liberdade da prestação do depoimento', consoante dispõe o $\mathrm{n}^{\circ} 2$ do art. $520^{\circ}$ a propósito da comunicação direta do tribunalcom o depoente. A testemunha pode ser questionada a tal propósito, com a cominação ínsita à falsidade de testemunho. Se disponíveis, poderão ser usados procedimentos tecnológicos que permitam ver, em $360^{\circ}$, o local onde se encontra a testemunha. No âmbito do negócio processual das partes, que preveja a inquirição da testemunha em local diverso de um tribunal, poderão as partes - querendo, financiando e à cautela - convencionar, acessoriamente, que a prestação do depoimento será supervisionada por notário, que atestará os termos do espaço envolvente da testemunha e a sua prestação de depoimento sem interferências de qualquer índole.

Por seu turno, o depoimento à distância pode também acarretar benefícios para a

\footnotetext{
${ }^{36}$ Tais como a redução de custos com as deslocações e a maior disponibilidade dos depoentes, razões pelasquais seguramente será ponderado no futuro o alargamento desta ferramenta a outros casos para além dos previstos no atual CPC.

37 Nos casos em que a audiência se tenha realizado totalmente por meios telemáticos e não tenha sido disponibilizado o link de acesso ao público em geral.

${ }^{38}$ Que, aliás, tem sido um dos princípios por que se têm pautado, ao longo dos anos, as diversas reformas das leis de organização judiciária. Manifestação disto mesmo pode encontrar-se na criação de secções de proximidade pela Lei de Organização do Sistema Judiciário, que visou precisamente colmatar a distância geográfica que resultou da supressão de alguns tribunais.

39 SOUSA, Luís Filipe Pires de. O sentido útil do princípio da imediação, 2020, disponível em: https://www.academia.edu/43470477/O_SENTIDO_ÚTIL_DO_PRINCÍPIO_DA_IMEDIAÇÃO.NOTAS_ A_PROPÓSITO_DO_ARTIGO_6o-A_DA_LEI, pp. 5 e 6 .
} 
busca da verdade material resultantes da circunstância de a testemunha ou a parte se sentirem menos nervosas e intimidadas na presença do tribunal, assim permitindo uma maior espontaneidade, verdade e clareza nas respostas.

Mas, por outro lado, a distância pode também acarretar impactos negativos ao nível do comportamento dos intervenientes ${ }^{40}$. Está estudado que a distância gera uma menor capacidade de empatia entre os operadores judiciários, afetando necessariamente o tipo de depoimento e a credibilidade que este gera no espírito do julgador ${ }^{41}$.

\subsection{O futuro: proposta de alteração do CPC}

Apesar de o regime vigente em tempos de pandemia não ter afetado diretamente o princípio da imediação, prevê-se que o mesmo não aconteça no rescaldo da mesma pandemia. Com efeito, na sequência de uma redução da atividade dos tribunais durante a crise pandémica prevê-se que o período pós-pandemia traga um aumento das pendências que urge combater.

Assim, com o objetivo de imprimir uma maior celeridade e eficácia à ação do sistema judicial o Governo apresentou uma proposta de alteração ao CPC (Proposta de Lei 92/XIV/2), publicada a 10 de Maio de 2021 na II série A do DR (n. ${ }^{\circ} 129$ ), que prevê, além de outros aspetos igualmente relevantes mas que não interferem no âmbito do nosso estudo, alterações quanto à forma de produção de algumas provas pessoais.

Em especial, chama-se a atenção para a proposta contida naquela Proposta de Lei que, através da alteração da atual redação dos arts. $517 .^{\circ}$ e $518 .^{\circ}$ do CPC, visa estimular e facilitar o depoimento testemunhal escrito ou previamente produzido no domicílio profissional de um dos advogados através da contrapartida de uma redução das custas processuais. A exposição de motivos da Proposta de Lei é clara relativamente a estas intenções:

No mais, no plano internacional são reconhecidas as vantagens de

\footnotetext{
${ }^{40}$ Muitas vezes como resultado de aspetos aparentemente tão secundários como o posicionamento da câmara, a distância a que está do depoente, a iluminação, a sonoridade, a qualidade da ligação, etc. Para estes aspetos chama a atenção SOUSA, Luís Filipe Pires de. "Julgamento presencial versus julgamento com telepresença. A pandemia e o futuro", Julgar, n. ${ }^{\circ} 44,2021$, Coimbra, Almedina, pp. 25 e ss.

${ }^{41}$ V. desenvolvimentos, assentes em estudos científicos, em SOUSA, Luís Filipe Pires de. "Julgamento presencial versus julgamento com telepresença. A pandemia e o futuro", Julgar, n. ${ }^{\circ} 44,2021$, Coimbra, Almedina, pp. 22 e ss.
} 
celeridade processual do recurso ao depoimento testemunhal escrito ou previamente produzidono domicílio profissional de um dos advogados, atualmente previstos nos artigos $517 .^{\circ}$ e $518 .^{\circ}$ do Código de Processo Civil, aprovado pela Lei n. ${ }^{\circ} 41 / 2013$, de 26 dejunho, na sua redação atual.

Trata-se de um modelo muito utilizado no regime processual civil francês e norte- americano, que demonstra reconhecidas vantagens para a celeridade e tempo de duração dos processos, mas que no sistema judicial português ainda tem utilizaçãomeramente residual.

Nessa medida, tendo em vista estimular as partes a recorrer a este meio de produçãode prova testemunhal estatui-se que as custas do processo são reduzidas a metade, sempre que, até ao despacho que marque a audiência final, for apresentada ata de inquirição da totalidade das testemunhas arroladas pelas partes.

Por outro lado, altera-se o regime do depoimento apresentado por escrito permitindo a sua utilização, sem a necessidade de autorização judicial nessesentido, desde que as partes estejam de acordo ou no caso de a testemunha ter conhecimento de factos por virtude do exercício das suas funções. Introduz-se, ainda, a obrigação do depoimento vir acompanhado de cópia de documento de identificação do depoente e indicação da existência de alguma relação de parentesco, afinidade, amizade ou dependência com as partes ou qualquer interessena ação.

Por último, neste conspecto, permite-se que o depoimento por escrito possa ser efetuado perante notário, bem como a possibilidade de o juiz, oficiosamente ou a requerimento das partes, determinar a renovação do depoimento na sua presença.

Em conformidade, propõe-se que os arts. $517 .^{\circ}$ e $518 .^{\circ}$ sejam alterados no sentido de a respetiva redação passar a ser a seguinte:

Artigo 517.…]

$1-[\ldots]$.

$2-[\ldots]$.

3 - Quando, até ao despacho que marque a audiência final, for apresentada ata de inquirição da totalidade das testemunhas arroladas pelas partes, as custas do processo são reduzidas a metade.

Artigo 518. $[\ldots]$

1 - O depoimento pode ser prestado através de documento escrito, datado e assinado pelo seu autor, com indicação da ação a que respeita e do qual conste relação discriminada dos factos e das razões de ciência invocadas:

a) Quando haja acordo das partes;

b) Se a testemunha tiver conhecimento de factos por virtude do exercício dassuas funções.

2 - O escrito a que se refere o número anterior é acompanhado de cópia de documento de identificação do depoente e indica se existe alguma relação de parentesco, afinidade, amizade ou dependência com as partes ou qualquer interesse na ação.

3 - O depoimento pode igualmente ser prestado perante notário, que o certifica e indaga das circunstâncias mencionadas no número anterior.

4 - Incorre nas penas cominadas para o crime de falsidade de testemunho quem, pela forma constante dos números anteriores, prestar depoimento falso. 
5 - Quando o entenda necessário, pode o juiz, oficiosamente ou a requerimento das partes, determinar, sendo ainda possível, a renovação do depoimento na sua presença.

6 -É aplicável o disposto no n. ${ }^{\circ} 3$ do artigo anterior.

Esta proposta em concreto relativa ao depoimento escrito das testemunhas, não obstante não ter sido consequência de qualquer experiência resultante do regime da pandemia, acaba por ser resultado da mesma por visar combater os efeitos dela resultantespara a demora da litigância judicial. Para além disso, a sua interferência com o princípioda imediação resulta evidente, merecendo, por isso, neste estudo especial referência.

Tal restrição ao princípio da imediação, aliás, acaba por ser o principal mote das críticas dirigidas a esta proposta, provindas dos mais variados sectores da comunidade jurídica.

A tal propósito, é emblemático o Parecer da Associação Sindical dos Juízes Portugueses $^{42}$, datado de Junho de 2021 que, referindo-se à proposta do art. 518. ${ }^{\circ}$ que prevê a facilitação da possibilidade de depoimento escrito das testemunhas, conclui o seguinte:

A redação proposta dispensa quer o requisito da impossibilidade ou grave dificuldade de comparência no tribunal quer a autorização do juiz, solução com quea Associação Sindical do Juízes Portugueses não concorda.

Um dos princípios basilares do Código de Processo Civil é o princípio da imediaçãoe da oralidade por via dos quais se enobrece a função de julgar e que são essenciaispara a apreciação dos meios probatórios e formação da convicção do Tribunal.

A valoração do depoimento de uma testemunha vai para além da linguagem verbal,assumindo a linguagem não verbal uma importância que é essencial na apreciaçãodo depoimento e na formação da convicção.

Sem prejuízo da possibilidade a que se reporta o $\mathrm{n}^{\circ} 5$ proposto, prescindir do requisito da impossibilidade ou grave dificuldade de comparência no tribunal e da autorização do tribunal significará prescindir do cerne da função de julgar o que não pode merecer concordância.

(...)

Sugere-se, assim, que seja condicionado o depoimento por escrito à impossibilidade ou grave dificuldade de comparência no tribunal e a autorização do tribunal nos termos atualmente previstos.

Também o Parecer do Conselho Superior do Ministério Público ${ }^{43}$, com o mesmo 
fundamento da violação da imediação, é especialmente crítico relativamente à proposta de alteração do art. 517. ${ }^{\circ}$ (depoimento prestado no domicílio profissional de advogado), uma vez que esta, em comparação com o art. 518. (depoimento escrito) prevê ainda menos garantias do que este:

Ora, a norma em causa, para além de colocar seriamente em risco o princípio da imediação, permitindo - e, mais, beneficiando, do ponto de vista económico - os casos em que toda a prova testemunhal arrolada seja inquirida por mandatário e nãopelo juiz que julgará a factualidade provada e não provada e decidirá da causa. Mais, o artigo 517. ${ }^{\circ}$ não prevê idênticas garantias que resultam, ainda assim, da redação proposta para o artigo $518 .^{\circ}$ daquela primeira norma, nada prevendo, por exemplo, quanto à possibilidade de o juiz determinar a renovação do depoimento na sua presença.

Por seu turno, o Parecer da Ordem dos Advogados ${ }^{44}$ chama ainda a atenção para os riscos da ampliação de um sistema de depoimento testemunhal sem passado entre nós, uma vez o depoimento escrito ou produzido no domicílio profissional de um dosadvogados reflete "a crença na vantagem de modelos importados, ainda que não testados".

Acresce que, independentemente das observações que a Proposta de Lei merece no que se refere a este aspeto do depoimento escrito em concreto e sua potencial violação do princípio da imediação, a verdade é que a regra do depoimento escrito, que não constituiuma novidade no sistema jurídico português, não é bem vista pela nossa comunidade jurídica, segundo já antes atestava um estudo da Fundação Francisco Manuel dos Santos, de Novembro de $2012^{45}$. Em geral, e apesar de se concordar que o testemunho escrito poderia acelerar o processo, considera-se que o testemunho escrito põe em causa a credibilidade e autenticidade do testemunho, como resulta de entrevistas feitas a juízes e advogados:

Os juízes consideram que o depoimento escrito vicia as regras do jogo, permitindoa intervenção dos advogados na elaboração do testemunho:

- Nós não somos psicólogos mas acabamos por ser com a prática que vamos adquirindo e por isso, só perante a imediação da presença da testemunha, da dinâmica pergunta/resposta, excitação, silêncio, atitude.

a5357357059326c6864476c3259554e7662576c7a633246764c325a6c596d5978597a64684c5441354e544 5744e444a6b4f5331684e474a684c546c6d4f44426a4d7a4e68596a4a6b4f4335775a47593d\&fich=febf1c7 a0951-42d9-a4ba-9f80c33ab2d8.pdf\&Inline=true

https://app.parlamento.pt/webutils/docs/doc.pdf?path=6148523063446f764c324679626d56304c334e7064 47567a4c31684a566b786c5a793944543030764d554e425130524d5279394562324e31625756756447397 a5357357059326c6864476c3259554e7662576c7a633246764c7a4e6b4e57466d4d4451794c5451304d546 b744e4755314f433168593249774c544d794e54686d4d44526b595752694e7935775a47593d\&fich=3d5af 042-4419-4e58-acb0-3258f04dadb7.pdf\&Inline=true

45 AAVV, Justiça Económica em Portugal: Gestão Processual e Oralidade, Estudo da Fundação Francisco Manuel dos Santos, Novembro de 2012, pp. 40 e ss. 
Também segundo um advogado,

Depoimento escrito ébatota, é viciar as regras do jogo. O depoimento escrito não vai ser feito pela testemunha e, portanto, avançar com isto é uma machadada no sistema, é uma ficção, uma fantasia. A lei admite-o em situações limite de ausência, de doença, mas isso implica o prévio acordo das partes, implica que depois possam pedir esclarecimentos, etc" (juiz) ${ }^{46}$.

“- Não é a mesma coisa (o depoimento escrito). A pessoa confronta-se consigo própria no que é que vai responder, se vai responder verdade, se vai responder mentira. A pessoa diz perante juramento que vai dizer a verdade, aquilo tem uma carga" ${ }^{47}$.

\section{5. (MUITO) BREVE CONCLUSÃO}

O regime de produção da prova de cariz pessoal em tempos de pandemia não afetou $o$ âmago da imediação, muito embora se possa entender que acabou por afetar outras garantias que, não obstante, se justificaram transitoriamente por razões de Saúde pública. Constituindo a Justiça e a Saúde Pública valores fundamentais da Sociedade, a solução encontrada parece ter sido a que melhor permitiu compatibilizar transitoriamente os dois valores referidos.

Já, pelo contrário, as alterações que se anteveem como consequência indireta da pandemia parecem sugerir que se avizinham restrições consideráveis ao princípio da imediação. Ora, no contexto pós-pandemia, a análise das restrições a valores fundamentais do Processo Civil já não poderá ser pautada pela justificação da proporcionalidade relativamente a outros valores como a Saúde Pública.

Resta saber se o objetivo de, através da celeridade, restabelecer a possível normalidade das pendências processuais será justificação bastante para aquelas restrições legislativas. Tudo dependerá da concretização da intenção legislativa mas apenas o futurodirá.

\section{REFERÊNCIAS:}

AAVV, Justiça Económica em Portugal: Gestão Processual e Oralidade, Estudo da Fundação Francisco Manuel dos Santos, Novembro de 2012.

ALEXANDRE, Isabel. “A fase da instrução e os novos meios de prova no Código de

\footnotetext{
${ }^{46}$ AAVV, Justiça Económica em Portugal: Gestão Processual e Oralidade, Estudo da Fundação Francisco Manuel dos Santos, Novembro de 2012, cit., p. 38.

${ }^{47}$ AAVV, Justiça Económica em Portugal: Gestão Processual e Oralidade, Estudo da Fundação Francisco Manuel dos Santos, Novembro de 2012, cit., p. 40.
} 
Processo Civil de 2013”, Revista do Ministério Público, 134, Abril/Junho 2013, pp. 9 e ss.

BELEZA, Maria dos Prazeres. "Julgamento de Facto em $1^{\text {a }}$ e $2^{\mathrm{a}}$ Instâncias", Jurismat, Portimão, 2020, n. ${ }^{\circ}$ 12, pp. 203 a 220.

FERNANDES, Manuel Domingos. "O novo código de processo civil e o duplo grau de jurisdição da matéria de facto", Julgar online, Julho 2014.

FREITAS, Lebre de. Introdução ao processo civil, 4ª ed., Gestlegal, Coimbra, 2017.

GERALDES, Abrantes. Recursos no NCPC, $2^{\mathrm{a}}$ ed., Coimbra, Almedina, 2013, p. 234.

GONÇALVES, Marco Carvalho. Atos Processuais e Prazos no âmbito da pandemia da doença Covid-19, Junho de 2020, disponível em: https://repositorium.sdum.uminho.pt/bitstream/1822/65830/1/Atos\%20processuais\% $20 \mathrm{e}$

\%20prazos\%20no\%20âmbito\%20da\%20pandemia\%20da\%20doença\%20Covid19\%20\%28Marco\%20Gonçalves\%29.pdf

MARQUES, J.P. Remédio. Acção Declarativa à Luz do Código Revisto, Coimbra Editora, Coimbra, 2007.

MESQUITA, Paulo Dá. “Alguns sinais sobre tendências actuais do processo penal português - convergências metodológicas sobre o contraditório, a prova, a imediação e a confiança nos juízes", Julgar, n. ${ }^{\circ}$ 25, 2015, pp. 109 e ss.

Parecer da Associação Sindical dos Juízes Portugueses, disponível em: https://app.parlamento.pt/webutils/docs/doc.pdf?path=6148523063446f764c3246796 26d56304c334e706447567a4c31684a566b786c5a793944543030764d554e42513052 4d5279394562324e31625756756447397a5357357059326c6864476c3259554e76625 76c7a633246764c7a59324e6d51304d7a466b4c546b324d7a55744e4751334e793035 4e6a46694c574e6b4d7a637a5a6a4e6c4d545177596935775a47593d\&fich=666d431 d-9635-4d77-961bcd373f3e140b.pdf \&Inline=true

Parecer da Ordem dos Advogados, disponível em: https://app.parlamento.pt/webutils/docs/doc.pdf?path=6148523063446f764c3246796 26d56304c334e706447567a4c31684a566b786c5a793944543030764d554e42513052 4d5279394562324e31625756756447397a5357357059326c6864476c3259554e76625 76c7a633246764c7a4e6b4e57466d4d4451794c5451304d546b744e4755314f433168 
593249774c544d794e54686d4d44526b595752694e7935775a47593d\&fich=3d5af04

2-4419-4e58-acb0-3258f04dadb7.pdf\&Inline=true

Parecer do Conselho Superior do Ministério Público, disponível em:

https://app.parlamento.pt/webutils/docs/doc.pdf?path=6148523063446f764c3246796

26d56304c334e706447567a4c31684a566b786c5a793944543030764d554e42513052

4d5279394562324e31625756756447397a5357357059326c6864476c3259554e 76625

76c7a633246764c325a6c596d5978597a64684c5441354e5445744e444a6b4f533168

4e474a684c546c6d4f44426a4d7a4e68596a4a6b4f4335775a47593d\&fich=febf1c7a-

0951-42d9-a4ba-9f80c33ab2d8.pdf\&Inline=true

PISSARRA, Nuno Andrade. "Audiências judiciais por videoconferência no processocivil",

Revista de Direito e Estudos Sociais, ano LXI, 2020, pp. 167 e ss.

SOUSA, Luís Filipe Pires de. "Julgamento presencial versus julgamento com telepresença.

A pandemia e o futuro", Julgar, n. ${ }^{\circ}$ 44, 2021, Coimbra, Almedina, pp. 13 ess.

SOUSA, Luís Filipe Pires de. O sentido útil do princípio da imediação, 2020,disponível em:

https://www.academia.edu/43470477/O_SENTIDO_ÚTIL_DO_PRINCÍPIO_DA_I

MEDIAÇÃO._NOTAS_A_PROPÓSITO_DO_ARTIGO_6o-A_DA_LEI

SOUSA, Miguel Teixeira de. Introdução ao Processo Civil, Lex, Lisboa, 2000, p.

65.

VARELA, João de Matos Antunes; BEZERRA, Manuel; NORA, Sampaio e. Manual de processo civil, $2^{\mathrm{a}}$ ed, Coimbra Editora, Coimbra, 1985.

VAZ, Alexandre Pessoa. Os grandes paradoxos da política judiciária nos últimos cinquenta anos, in Da Crise da Justiça em Portugal, s/d, disponível em: https://portal.oa.pt/upl/\%7B41a8971d-e10e-4a4a-b136-cc5dcc624371\%7D.pd 